\title{
JOHN SIMONS
}

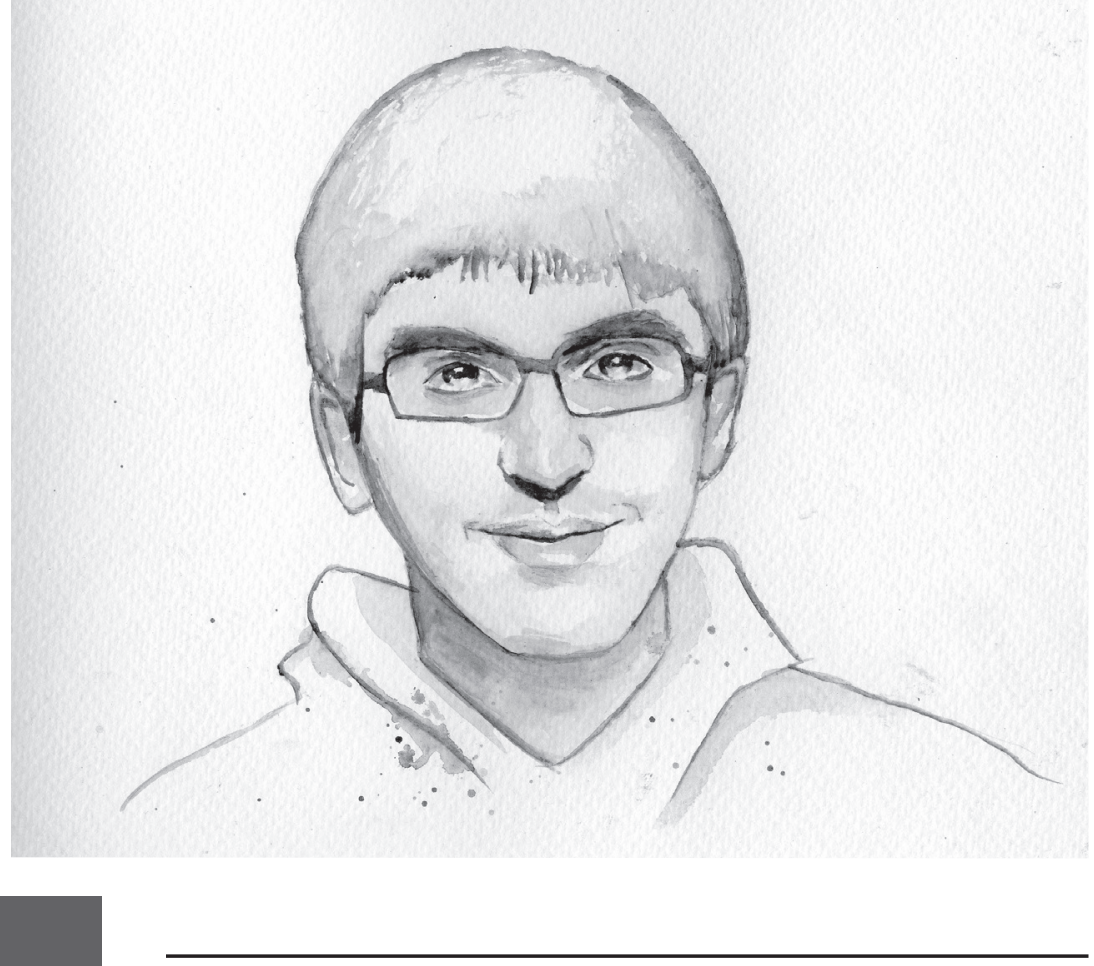

John Simons is a sophomore at the University of Pittsburgh. He studies in the fiction track of the English Writing major and works at the DePaul School for Hearing and Speech. Don't bother asking him how his work gets published. He's just as confused as you are. 


\section{"A MEMORIAL TO 'THE VAINGLORIOUS DEATH BY FIRE OF MY COMRADES ON THE STREETS OF MIDDLE AMERICA DURING THE OUTBREAK"}

Brains.

Braaaaaaains.

Braaaaaaaaaaaaaaaains.

Brains?

BBBBRRRAAAAAAAAAAAINNNNNNNNNNNS.

BRAAAAAIINNNS.

BRAINS. BRAINS. Brains. Brains.

Braaaaaaaainsssssssss. Braaaaaaaaiiiiinnnnnnsssssss.

Brains. Brains. Brains.

Braaaaains.

Brains. 